\title{
Flbstracts.
}

\section{Iheurologe. NEUROPATHOLOGY.}

[65] The pathology of amyotrophic lateral sclerosis (Zur Pathologic der amyotrophischen Lateralsklerose).-Naito. Jahrb. f. Psychiat. $u$. Neurol., 1922, xlii, 90.

THE author of this paper, impressed with the difficulty of deciding from the terminal pathological findings the nature of the process at work in any chronic nervous disease, and believing, on account of earlier findings, that in amyotrophic lateral sclerosis the process is an inflammatory one, sought through a number of brains of sufferers from this disease for a patch of recent inflammation and eventually found one. It lay in the motor cortex, and the remainder of the cortex was little affected: the pyramidal cells were considerably damaged and the cells of the other layers also suffered; there was a glia reaction which was of an inflammatory character. Some vessels in the brain substance showed great perivascular infiltration and the infiltrating cells were nearly all lymphocytes.

The author was unable to find any similar patches in other parts of the brain or in the spinal cord. He concludes that amyotrophic lateral sclerosis is the result of a chronic inflammatory process and is inclined to think that the inflammation is due, not to a toxin, but to an infection.

J. P. M.

[66] The pathology of congenital hydrocephalus (Zur Pathologie des kongenitalen Hydrozephalus).-Kuвo. Arbeit. Neurol. Inst. Weiner Univ., 1922, xxiv, 49.

THe anatomical study of congenitally hydrocephalic brains has failed hitherto to demonstrate the changes which give rise to the retention of the cerebrospinal fluid, let alone the cause of such changes. Kiyoyi Kubo, in his examination of three such brains, has not met with greater success than earlier workers and has not succeded in showing the cause of the hydrocephalus. Like his predecessors, he must have laboured, for part of the time at any rate, under the disadvantage of having very incomplete knowledge of the course of the circulation of the fluid, for his examination of the first brain was made in 1918, and the work of Dandy and Blackfan was not published till 1919. There is no indication that he became acquainted with their work before finishing his paper, and he does not refer to it in his bibliography.

Dandy and Blackfan showed that the fluid was absorbed from the sub- 
arachnoid space, particularly over the cerebral hemispheres. Kubo does not mention the arachnoid at all in describing his findings, except in the case of the first brain. In it he says there were streaks of yellowish exudate, becoming organized, on the ependyma, and "in the leptomeninges of the cerebrum and cerebellum, especially in the neighbourhood of the cisterna cerebello-medullaris. Also the leptomeninges in the region of the foramen of Marchandi (Luschka) were firm and thickened."

In all his cases the ventricles were so distended that the brain substance was in many places less than half a centimetre in thickness; the ependyma was in all the cases complete or nearly so ; beneath it there was a great excess of glia, and in one case some small areas of softening were present. The cortex in every case showed some microgyria ; the layers of the cortex were quite definitely marked, but the cells of which they were composed always showed some arrest of development, neuroblastic forms being abundant. It is interesting to note that all three brains showed some deposit of calcium either in vessel walls or free in the brain tissue.

Towards the end of the paper, an interesting experimental finding is quoted from a paper by D'Abundo, viz., that an artificial subcortical lesion in new-born animals usually produces a cyst in the brain substance (presumably by inflammation), but that if the lesion reaches the ventricle, hydrocephalus arises, both of the injured side and of the opposite side of the brain.

Basing his theory on these results of D'Abundo's, Kubo ascribes the causation of hydrocephalus to trauma early in intrauterine life, believing that the trauma produces subcortical softenings which reach to the ventricle.

J. P. Martin.

The pathology of tumours of the cerebello-pontine angle (Zur Pathologie der Kleinhirnbrückenwinkel - Tumoren). - Nishikawa. Arbeit. Neurol. Inst. Weiner Univ., 1922, xxiv, 15.

THE key to this somewhat involved paper lies in the sentence: "But now it has become apparent that central as well as peripheral changes occur and that they must be closely connected with the acoustic nerve tumours." For the paper is concerned with changes within the brain occurring in cases of acoustic nerve tumours more than with the direct examination or discussion of the tumours themselves. The author found in Antoni's monograph references to twenty-one cases of acoustic nerve tumour in which some new growth in the brain was present, and he now describes a case of his own in which there were numerous small focal changes in the cortex. He was led to conclude that the intracerebral growths found by different investigators are of three different kinds : (1) a local increase of glia in such a way that its proliferation gives rise to circumscribed 'knots'; the glia at the same time 'shows a pathological reaction'; (2) masses of fibrous tissue, with peculiar alterations in the blood vessels : and (3) tumours containing nerve fibres and of the type of neurinomata.

The first group comprises his own case and most of the others : the glial foci are usually about the size of a pinhead; they appear on the surface of 
the brain and the pia is adherent to them. Nishikawa sees in them evidence of that over-activity of growth which is responsible for the tumour on the acoustic nerve. The tumours of the second group arise from the perivascular connective tissue, and they are associated with hyaline and other changes in the vessel walls. Those of the third group - the true neurinomata-originate, he believes, from the small nerves supplying either the pia or the blood vessels.

The writer also points out the frequency of the presence of ganglion cells in the white matter of the brain in cases of acoustic nerve tumour, and he regards it as an indication of a developmental fault of the type likely to give rise to tumour-formation.

By examination of some more acoustic tumours, the author shows that areas of definite glia may occur in them and also that fully developed ganglion cells may be present. The terminal part of the paper deals with the formation of cysts in acoustic nerve tumours as a result of softening, of hæmorrhage or of oedema and swelling.

J. P. Martin.

The histological proof of diffusion of the cerebrospinal fluid into the pia mater and brain substance in general paralysis (Der histologische Nachweis der Liquordiffusion in der Pia und im Nervenparenchym bei der Paralyse).-Gennerich. Münch med. Woch., 1923, lxx, p, 525.

GENNERICH points out that diffusion of the cerebrospinal fluid into the brain substance is one of the most important factors in the pathogenesis of general paralysis and tabes, for it alters the metabolism of the nerve tissue in such a way that the latter, a parenchymatous tissue, can become a prey to a parasite which normally confines itself to interstitial tissue. He conceives the sequence of events in general paralysis thus : In consequence of (inadequate) treatment, the virulence of the syphilitic infection is mitigated, and therefore the body defence-reactions are weakened; hence a very chronic latent syphilitic meningitis arises and leads to adhesions of the pia to the cortex and to a fibrous degeneration (sclerosis) of the pia ; in proportion to the amount of this adhesion and degeneration, there is a more or less abundant invasion of the cortical parenchyma by the cerebrospinal fluid, for one of the functions of the pia is to prevent the brain tissue from becoming soaked with the watery liquid which surrounds it.

In order to demonstrate the diffusion of the cerebrospinal fluid into the cortex, the author introduced 175 cc. of a one per cent. solution of potassium ferrocyanide by lumbar puncture into the corpse of a patient who had died of general paralysis; he then removed the brain and spinal cord and steeped them for a quarter of an hour in a one per cent. solution of copper sulphate ; this produced a reddish brown deposit of ferrocyanide of copper in those parts which had been permeated by the potassium ferrocyanide. Microscopic sections were then made from different parts of the brain, and it was found that at the places where the pia was thickened and adherent, the cortex was infiltrated with copper ferrocyanide to its third or fourth layer; the pia was infiltrated throughout; the blood vessels showed the copper deposit in the medial coats of their walls but not in the intima or adventitia. 
Clinical manifestation of the permeation of brain substance by the cerebrospinal fluid is provided by the untoward consequences which sometimes follow the introduction of neosalvarsan into the lumbar theca. Unless the solution is run in slowly under very little pressure, fits and sudden exacerbations of the paralysis are liable to occur, and these the author attributes to a sudden increase of the watery infiltration of the cortex owing to the sudden increase of pressure in the cerebrospinal fluid.

J. P. M.

[69] The frequency of a positive Wassermann reaction in the cerebrospinal fluid when it is negative in the blood (Die Häufigkeit von positivem Liquor-Wassermann neben negativem Blut-Wassermann).Eskuchen. Münch. med. Woch., 1923, lxxv, p. 527.

Ever since the Wassermann test began to be applied to the cerebrospinal fluid numerous cases have been reported in which the reaction was positive in the fluid and negative in the blood. But the frequency with which this relation occurs has given rise to some argument. In $1920 \mathrm{Kafka}$, from an examination of 124 cases of general paralysis, found the Wassermann positive in the fluid but negative in the blood, on the same day, in nearly 20 per cent. His figures were quickly challenged by Plaut, who in his records of 1,420 cases of this same disease found no such instances, though there were eight cases $(0 \cdot 6$ per cent.) in which the reaction was negative in both blood and fluid. A new factor was introduced into the discussion when Eicke and Löwenberg showed that the inactivation of fluid, by heating it to $56^{\circ} \mathrm{C}$. for half an hour, made a great difference in its reaction, a weakly positive one becoming negative and others becoming less strongly positive than before.

Stimulated by the publication of these discordant figures, Eskuchen has examined his records and now publishes his figures not only for general paralysis but for cerebrospinal syphilis and tabes as well. He has found a positive reaction in the fluid when it was negative in the blood in four out of seventy-two cases of general paralysis (5.5 per cent.), in fourteen out of 113 cases of cerebrospinal syphilis $(12 \cdot 4$ per cent.), and in fifteen out of 161 cases of tabes $(9 \cdot 3$ per cent.). This makes a total of thirty-three cases out of 346 or 9.53 per cent.-a figure which he says surprised himself, for he had excluded all cases which had received recent treatment.

Among his 346 cases diagnosed as mentioned there were in all ninetyseven in which the blood reaction was negative; of these, thirty-three (or 34 per cent.) gave a positive reaction in the cerebrospinal fluid, so that the advisability of testing the fluid when the blood gives a negative reaction is obvious.

J. P. M.

[70] The characteristics of the cerebrospinal fluid in post-diphtheric paralysis -Regan, Regax and Wilsox. Amer. Jour. Dis. Children, 1923, xxv, 284.

THE cerebrospinal fluid was examined twenty-eight times in each of sixteen cases of post-diphtheric paralysis; twenty-two examinations were made in the first four weeks. Two-thirds of the cases showed generalized paralysis. 
The limpidity, tension and Wassermann reaction in all cases were normal. In two-thirds of the cases there was slight increase $( \pm$ to $3+)$ of the globulin content (method of estimating not stated). The cell count per c.mm. varied from 0 to 10, i.e., was normal. In every case, except one in which the nervous symptoms were minimal, there was a positive colloidal gold reaction. This occurred in the middle zone (luetic), and was slight, rarely reaching 3. It occasionally extended into the higher dilutions. Both globulin and gold reaction became normal as the paralysis disappeared.

M. A. Blandy.

\section{SENSORIMOTOR NEUROLOGY.}

[71] Two peculiar manifestations of prolonged epidemic encephalitis : respiratory disturbance, insomnia. (Deux manifestations particulières de l'encéphalite épidémique prolongée : forme respiratoire, forme insomnique).-Pierre Marie and Mlle. G. Lévy. Revue neurol., 1922, xxxviii, 1233.

A. MAvy observers have previously called attention to disturbances of the respiratory function in this disease (reference is made to their papers). Symptoms of this nature may be classified as :-

(1) Respiratory disturbances properly so-called. These are : polypnœa occurring either continuously or in nocturnal paroxysms; disturbances of the normal rhythm in the form of occasional or periodic phases of apnoca ; and sighing.

(2) Paroxysmal coughing without expectoration.

(3) Respiratory tics (sniffing, blowing and spitting) and abnormal sensations in the nose and larynx.

13. Lethargy is far from being the only disturbance of the normal sleeprhythm. Insomnia is often encountered in various forms. Invasion of the normal cycle of sleep and wakefulness, retardation of the sleep hour, restless slecp, somnambulism, periodic excitement at fixed hours in the evening, are described in detail.

A series of cases is briefly recorded to illustrate the two groups of symptoms. The paper, which is rich in clinical detail, should be consulted in the original by those interested in the subject.

\section{P. S.}

[72] Post-encephalitic contracture of the tongue (Note sur un cas de contracture de la langue post-encéphalitique).--E. Christias. Revue neurol., 1922, xxxviii, 1186.

A wound of thirty-two suffered in February, 1920, from a febrile illness diagnosed at the time as influenza. Six months later she noticed an abnormal tendency to muscular fatigue and slowness of movement. Towards the beginning of 1922 her speech became embarrassed at times on account of stiffness of the lips and tongue. Examined in 1922, she showed general muscular rigidity and slowness of movement of the Parkinsonian type.

The most remarkable feature, however, was the contracture of the tongue, which at rest took the form of a ball held between the teeth. The 